\title{
HUBUNGAN POLA PENGASUHAN DENGAN PERKEMBANGAN ANAK BALITA DI TEMPAT PENITIPAN ANAK (TPA) AISYIYAH KECAMATAN KOTA KABUPATEN BANGKALAN
}

\author{
Badriyah, Sulastri, Anis Nur Laili \\ Prodi D III Kebidanan Bangkalan Jurusan kebidanan Poltekkes Kemenkes Surabaya \\ Jalan Soekarno-Hatta No. 32 Bangkalan 69116 \\ E-mail : badriyahsidik@yahoo.co.id
}

\begin{abstract}
ABSTRAK
Anak sebagai bagian dari generasi muda merupakan mata rantai yang sangat penting dan menentukan dalam upaya menyiapkan masa depan bangsa dan Negara dan periode penting dalam tumbuh kembang anak adalah masa balita, karena pada masa balita ini perkembangan kemampuan berbahasa, kreatifitas, kesadaran sosial, emosional dan intelegensi berjalan sangat cepat dan merupakan landasan perkembangan berikutnya. Kebanyakan seorang ibu, di kota besar pada umumnya sibuk bekerja sehingga kurang mempunyai waktu yang cukup untuk bergaul dan bermain dengan anak-anaknya, disebabkan banyaknya pekerjaan di luar rumah tangganya. Dengan demikian jalan alternatif yang ditempuh oleh orang tua untuk permasalahan dalam menjaga dan merawat anak salah satunya adalah dengan menitipkan anak di TPA atau tempat penitipan anak.

Tujuan dari penelitian ini adalah menganalisis hubungan pola pengasuhan dengan perkembangan anak balita di tempat penitipan anak. Jenis penelitian ini adalah analitik dengan rancangan penelitian adalah cros sectional. Variabel independen yaitu pola asuh serta variabel dependen perkembangan anak. Populasi dalam penelitian ini adalah seluruh balita di TPA Aisyiah sebanyak 23 balita dengan teknik sampling accidental sampling. Pengumpulan data menggunakan lembar observasi dan kuisioner serta dianalisis dengan uji statistic korelasi spearman rank. dengan tingkat signifikan (a) 0,05.

Hasil penelitian menunjukkan bahwa dari seluruh pengasuh memiliki gaya demokratis (100\%) dan dari 23 Balita 20 anak (86,9\%) perkembangannya sesuai, 2 anak meragukan $(8,7 \%)$ dan 1 anak $(4,4 \%)$ terdapat penyimpangan perkembangan. Dari penelitian ini hubungan variabel pola asuh dan perkembangan anak tidak dapat dianalisis karena seluruh pengasuh mempunyai pola asuh yang sama. Sebaiknya untuk penelitian selanjutnya menggunakan 2 tempat yang berbeda agar terdapat variasi jenis pola asuh sehingga analisis statistik dapat dilakukan.
\end{abstract}

Kata kunci : Perkembangan, balita, pola asuh, TPA

\section{PENDAHULUAN}

Anak sebagai bagian dari generasi muda merupakan mata rantai yang sangat penting dan menentukan dalam upaya menyiapkan masa depan bangsa dan negara dan periode penting dalam tumbuh kembang anak adalah masa balita, karena pada masa balita ini perkembangan kemampuan berbahasa, kreatifitas, kesadaran sosial, emosional dan intelegensi berjalan sangat cepat dan merupakan landasan perkembangan berikutnya. Perkembangan moral serta dasar-dasar kepribadian juga dibentuk pada masa ini. Salah satu dari prinsip perkembangan juga mengatakan 
bahwa perkembangan awal anak merupakan tahapan yang lebih kritis dari tahapan perkembangan selanjutnya, karena masa balita merupakan awal dari rangkaian perkembangan manusia, maka perkembangan pada masa ini mempnyai arti yang sangat penting bagi keberhasilan perkembangan pada tahap-tahap berikutnya (Santrock, 2009).

\section{Dari data WHO (World Health} Organization) tahun 2009 menunjukkan lebih dari $60 \%$ anak mengalami keterlambatan pada pekembangannya. Demikian pula data dari Dinas Kesehatan Provinsi Jawa Timur tahun 2011 menyebutkan 70\% anak mengalami keterlambatan pada perkembangannya (Rini, 2013).

Dampak perkembangan anak yang kurang baik pada awal masa kanak-kanak sering terjadi secara serius dan bisa dilihat dari pola asuh orang tua terhadap anaknya. Pola asuh yang otoriter ditandai orangtua yang melarang, memaksa, dan menghukum anak, akan membuat anak mempunyai karakteristik yang penakut, pendiam, gemar menentang, suka melanggar norma-norma dan cemas sehingga anak tidak popular diantara teman-teman sebayanya, ia tidak hanya akan merasa kesepian tetapi yang lebih penting lagi ia kurang mempunyai kesempatan untuk belajar berperilaku sesuai dengan harapan lingkungannya.

Setiap orang tua perlu memahami dan mengetahui tahap-tahap perkembangan anak sehingga mudah dalam mendidik dan membina anak. Oleh karena itu hal yang perlu diingat adalah bagaimana pola asuh atau bentuk asuhan yang diterapkan orang tua harus sesuai dengan perkembangan anak, agar tidak terjadi kesalahan dalam mengasuh buah hatinya karena sebagai perwujudan dari tanggung jawab orang tua dalam mendidik dan membina anak. Tetapi, yang menjadi permasalahan disini adalah ketika para orang tua terutama seorang ibu sibuk bekerja dalam meniti karir, sehingga kewajiban mendidik dan merawat anak terabaikan dan dialihkan kepada seorang pengasuh atau juru rawat, tentu saja ini akan berpengaruh terhadap perkembangan tingkah laku anak (Soetjiningsih, 2017).

Kebanyakan seorang ibu, di kota besar pada umumnya sibuk bekerja sehingga kurang mempunyai waktu yang cukup untuk bergaul dan bermain dengan anak-anaknya, disebabkan banyaknya pekerjaan di luar rumah tangganya. Dengan demikian jalan alternatif yang ditempuh oleh orang tua untuk permasalahan dalam menjaga dan merawat anak salah satunya adalah dengan menitipkan anak di TPA atau tempat penitipan anak. Dalam hal ini tempat penitipan anak merupakan upaya yang terorganisasi dalam mengasuh anak-anaknya khususnya balita di luar rumah orang tuanya selama beberapa jam dalam satu hari apabila asuhan orang tua kurang dapat dilaksanakan secara lengkap. Sarana penitipan anak ini hanya sebagai pelengkap terhadap asuhan orang tua dan bukan sebagai pengganti asuhan orang tua (Maimunah, 2011). 
Di dalam TPA atau tempat penitipan anak ini biasanya anak diasuh oleh seorang pengasuh atau disebut sebagai inang. Para pengasuh atau inang disini bertugas mengawasi dan menjaga anak selama ditinggal oleh orang tuanya. Maka perbedaan individual setiap anak mesti diperhatikan seorang pengasuh, karena hal ini anak harus dipandang sebagai salah satu sosok utuh yang mandiri dan berbeda satu dengan yang lain dalam segala hal. Oleh karena itu, sudah tentu orang tua akan lebih suka apabila anak anaknya tidak mendatangkan kesulitankesulitan dengan aneka macam tingkah lakunya yang serba aneh selama berada dalam tempat penitipan anak (TPA) karena masa-masa balita merupakan masa yang paling rawan dalam perkembangannya. Maka di dalam mengasuh anak, para pengasuh harus dibekali filosofi manajemen anak, sehingga dalam mengasuh dan merawat anak-anak selama di tempat penitipan anak dapat mengikuti prosedur pola asuh yang diterapkan sesuai dengan perkembangan anak masa balita. Cara ini dianggap yang paling baik untuk mengetahui perkembangan anak dalam memperhatikan ciri-ciri anak dalam setiap tingkat usianya.

Berdasarkan pernyataan tersebut di atas, penulis tertarik untuk mengetahui pola asuh yang diterapkan anak usia balita yang terdapat di dalam TPA atau tempat penitipan anak sebagai akibat kesibukan orang tua terutama seorang ibu bekerja meniti karir sehingga berdampak terhadap perkembangan anak. Dengan demikian untuk membuktikan hal tersebut, penulis akan mengadakan penelitian secara langsung di tempat penitipan anak (TPA) Aisyiah kecamatan Kota Bangkalan dengan judul: hubungan pola pengasuhan dengan perkembangan anak balita di tempat penitipan anak (TPA) Aisyiyah Kecamatan Kota Kabupaten Bangkalan

Tujuan penelitian ini adalah menganalisis hubungan pola pengasuhan dengan perkembangan anak balita di tempat penitipan anak (TPA) Aisyiyah kecamatan Kota kabupaten Bangkalan.

\section{METODE PENELITIAN}

Penelitian ini merupakan jenis penelitian analitik dengan cross sectional. Populasi dalam penelitian ini adalah seluruh balita di TPA Aisyiah Kecamatan Kota, Kabupaten Bangkalan bulan April 2017 sebanyak 24 balita yang juga merupakan subjek penelitian. Teknik sampling menggunakan jenis non probability sampling dengan accidental sampling dengan besar sampel 23 balita. Dalam penelitian ini terdiri dari variabel independen yaitu pola asuh serta variabel dependen perkembangan anak. Data pada variabel pola asuh di TPA dikumpulkan menggunakan kuesoner. Sedangkan untuk mengetahui perkembangan anak dengan menggunakan format KPSP. Data yang diperoleh dianalisis dengan uji statistic korelasi spearman rank dengan tingkat signifikan (a) 0,05. Penelitian ini dilakukan di TPA Aisyiah Kecamatan Kota, Kabupaten 
Bangkalan bulan April sampai dengan minggu kedua bulan Oktober 2017.

\section{HASIL PENELITIAN}

\section{Data Umum Responden}

Pada data umum akan disajikan hasil pengumpulan data yang meliputi nilai sentral responden anak dan distribusi tingkat pendidikan para pengasuh pada tabel 1 .

Tabel 1. Tabel nilai Sentral karateristik responden anak.

\begin{tabular}{|c|c|c|c|}
\hline No. & Karateristik responden anak & Hasil & Persentase \\
\hline \multirow[t]{5}{*}{1} & Usia & & \\
\hline & - Minimal & 32 & \\
\hline & - Maksimal & 60 & \\
\hline & - Rata-rata & 46,6 & \\
\hline & - SD & 9,4 & \\
\hline \multirow[t]{5}{*}{2} & Berat badan anak & & \\
\hline & - Minimal & 10 & \\
\hline & - Maksimal & 22 & \\
\hline & - Rata-rata & 14,6 & \\
\hline & - SD & 2,8 & \\
\hline \multirow[t]{5}{*}{3} & Tinggi Badan anak & & \\
\hline & - Minimal & 85 & \\
\hline & - Maksimal & 110 & \\
\hline & - Rata-rata & 99,7 & \\
\hline & - SD & 8,03 & \\
\hline \multirow[t]{5}{*}{4} & Lingkar kepala & & \\
\hline & - Minimal & 48 & \\
\hline & - Maksimal & 54 & \\
\hline & - Rata-rata & 49,9 & \\
\hline & - SD & 1,42 & \\
\hline \multirow[t]{3}{*}{5} & Pendidikan pengasuh & & \\
\hline & - SLTA & 6 & $60 \%$ \\
\hline & - Perguruan Tinggi & 4 & $40 \%$ \\
\hline
\end{tabular}

Sumber: perolehan data dari lapangan

\section{Data Khusus}

1) Pola Asuh

Dari hasil pengumpulan data menunjukkan bahwa mayoritas Pola Pengasuhan Anak adalah sebanyak 10 orang pola asuh demokratis (100\%). Untuk lebih jelasnya gambaran Pola Pengasuhan Anak dapat dilihat ditabel 2 di bawah ini.
Tabel 2 Distribusi Frekuensi Pola Pengasuhan Anak di TPA Aisyiah Kecamatan Kota Kabupaten Bangkalan bulan Juli 2017

\begin{tabular}{lcc}
\hline Pola Asuh & Frekuensi & $\begin{array}{c}\text { Persentase } \\
(\%)\end{array}$ \\
\hline Demokratis & 23 & 100 \\
Otoriter & 0 & 0 \\
Permisif & 0 & 0 \\
\hline Total & $\mathbf{2 3}$ & $\mathbf{1 0 0}$ \\
\hline \multicolumn{2}{l}{ Sumber: perolehan data dari lapangan }
\end{tabular}


2) Perkembangan

Dari hasil pengumpulan data menunjukkan bahwa mayoritas perkembangan anak adalah sesuai sebanyak 20 anak (86.94\%). Untuk lebih jelasnya gambaran perkembangan anak dapat dilihat ditabel 3 di bawah ini.

Tabel 3 Distribusi Frekuensi Perkembangan Anak di TPA Aisyiyah Kecamatan Kota Kabupaten Bangkalan bulan Juli 2017

\begin{tabular}{lcc}
\hline Perkembangan & Frekuensi & $\begin{array}{c}\text { Persentase } \\
(\%)\end{array}$ \\
\hline Sesuai & 20 & 86,9 \\
Meragukan & 2 & 8,7 \\
Penyimpangan & 1 & 4,4 \\
\hline Total & $\mathbf{2 3}$ & $\mathbf{1 0 0 . 0 0}$ \\
\hline
\end{tabular}

Sumber: perolehan data dari lapangan

Dari hasil penelitian ini hubungan variabel pola asuh dan perkembangan anak tidak dapat dianalisis karena seluruh pengasuh mempunyai pola asuh yang sama yaitu demokratis.

\section{PEMBAHASAN}

\section{Variabel Pola Asuh}

Dari hasil pengumpulan data menunjukkan bahwa pola pengasuhan anak di tempat penitipan anak Aisyiah Bangkalan $100 \%$ demokratis. Pola asuh demokratis adalah pola asuh pada anak yang memberi kebebasan pada anak untuk berkreasi dan mengeksplorasi berbagai hal sesuai dengan kemampuan anak dengan sensor batasan dan pengawasan yang baik dari orangtua atau pengasuhnya (Mansur 2005).
Hal ini karena para pengasuh di TPA Aisyiah Bangkalan sudah dapat pembinaan dari kepala TPA tentang cara mengasuh anak yang benar, dan $40 \%$ para pengasuhnya berpendidikan tinggi sehingga bisa memberikan contoh kepada pengasuh yang lain tentang cara mengasuh anak. Selain itu, lingkungan di TPA Aisyiah Bangkalan adalah sekolah PAUD dan TK yang sudah terakreditasi $B$ yang dilengkapi dengan fasilitas bermain anak.

\section{Variabel Perkembangan}

Dari hasil pengumpulan data menunjukkan bahwa mayoritas perkembangan anak di tempat penitipan anak Aisyiah Bangkalan adalah dalam kategori sesuai sebanyak 20 anak (86.9\%), meragukan 2 anak (8,7\%) dan menyimpang 1 anak (4,4\%). Anak yang sehat memiliki nilai perkembangan yang sesuai, sedangkan terdapat anak yang merasa asing atau takut pada pemeriksa yang tidak dikenalnya sehingga nilai perkembangannya meragukan.

\section{Hubungan Pola Asuh dengan Perkembangan Anak}

Berdasarkan penelitian didapatkan bahwa pola asuh 100\% dengan pola demokratis sehingga analisis secara statistik tidak dapat dilakukan. Pola asuh di TPA merupakan bagian kecil dari faktor-faktor yang mempengaruhi perkembangan, apalagi anak di TPA hanya antara 7 sampai 8 jam, 
waktu terbanyak adalah dirumah bersama keluarganya (Patmonodewo, 2003).

Menurut Wiyani (2012), faktor lain yang mempengaruhi perkembangan anak antara lain :

a) Environmental factors (rumah, penghasilan, pekerjaan, pendidikan )

b) Biological factors (jenis kelamin, kesehatan umum, kesehatan mental )

c) Interpersonal relationships (kedekatan, pola asuh orang tua, jaringan social )

d) Early environments and experiences (Pengalaman dan lingkungan sebelumnya )

Interaksi dengan manusia lain merupakan suatu hal yang sangan penting bagi seorang anak. Kontak mata, senyuman, memberikan lingkungan untuk mereka agar dapat berkomunikasi dengan baik, adanya pertukaran makna dalam berkomunikasi, dan keterlibatan orang tua akan membantu mengembangkan dunia mereka dalam berkomunikasi atau berhubungan dengan orang lain (Fadlillah, M\&Khorida, LM., 2013).

Sebaliknya, informasi kepada orang tua tentang kebiasaan pengasuhan di TPA diperlukan agar anak tidak mengalami perbedaan perlakuan pengasuhan baik di rumah ataupun di TPA. Faktor lain yang menyebabkan penyimpangan perkembangan anak di TPA Aisyiah juga bisa karena kurangnya tenaga pengasuh, jumlah pengasuh hanya 10 orang sedangkan jumlah bayi dan anak balita di TPA Aisyiah sebanyak 54 anak. Hal ini tidak sesuai dengan rasio pengasuh yang seharusnya 1 pengasuh 3 anak (Kasina, 2005).

Menurut Sunarti (2003), pengasuhan juga menyangkut aspek manajerial, berkaitan dengan kemampuan merencanakan, melaksanakan, mengorganisasikan, serta mengontrol atau mengevaluasi semua hal yang berkaitan dengan pertumbuhan dan perkembangan anak. Maka faktor pengasuh dan faktor pendukung di TPA Aisyiah sangat berperan.

Dalam setiap kegiatan tentu tidak lepas dari adanya faktor pendukung. Dalam kegiatan pengasuhan di TPA Aisyiah terdapat faktor pendukung yang membantu lancarnya proses kegiatan pengasuhan bagi anak usia dini. Faktor pendukung kegiatan pengasuhan terhadap anak usia dini di TPA Aisyiah adalah mempunyai letak yang strategis dan biaya penitipan yang terjangkau Selain karena letaknya yang strategis dan biaya yang terjangkau menjadi faktor pendukung di dalam pengasuhan TPA Aisyiah, adanya hubungan komunikasi yang baik antara pengasuh dan orang tua, latar belakang pengasuh yang sabar mengahadapi anak serta suasana TPA yang banyak alat bermain membuat anak betah atau nyaman. Di TPA, anak jadi bisa bersosialisasi dengan teman-temannya daripada di rumah.

\section{KESIMPULAN DAN SARAN}

\section{Kesimpulan}

Berdasarkan hasil penelitian maka dapat ditarik kesimpulan bahwa pola asuh 
para pengasuh di TPA Aisiyah adalah demokratis dan perkembangan anak balita sebagian besar adalah sesuai dengan usia perkembangannya.

\section{Saran}

Sebaiknya jumlah pengasuh di tempat penitipan anak ditambah sesuai rasio anak dengan perbandingan 1 berbanding 3 , agar anak mendapatkan perhatian dan memiliki keterdekatan dengan pengasuhnya. Pada anak yang perkembangannya mengalami penyimpangan dapat diberikan stimulasi/ rangsangan dengan mengajak anak bermain, sosialisasi anak, serta melibatkan ibu dan keluarga terhadap kegiatan anak.

Sebaiknya untuk penelitian selanjutnya menggunakan 2 tempat yang berbeda agar terdapat variasi jenis pola asuh sehingga analisis statistik dapat dilakukan.

\section{DAFTAR PUSTAKA}

Fadlillah, M \& Khorida, L M., 2013, Pendidikan Karakter Anak Usia Dini: Konsep \& Aplikasinya dalam PAUD. Yogyakarta: Ar-Ruzz Media.

Kasina, A \& Hikmah, 2005, Perlindungan dan Pengasuhan Anak Usia Dini, Departemen Pendidikan Nasional, Jakarta.

Maimunah, H., 2011, Pendidikan Anak Usia Dini. Yogyakarta. Diva Press

Mansur, 2005, Pendidikan Anak Usia Dini Dalam Islam, Pustaka Pelajar , Yogyakarta.
Patmonodewo, S., 2003, Pendidikan Anak Pra Sekolah,Rinika Cipta. Jakarta.

Rini, R.S \& Nikmah N., 2013, Hubungan Pola Asuh Orang Tua dengan perkembangan anak usia 3-5 tahun di TK PGRI kangenan desa langkap kecamatan burneh kabupaten bangkalan. Di akses tanggal 17 Januari 2017, http://www.stikes-insanseagung.ac.id/wpcontent/uploads/2015/04/No.3-PublikasiJurnal-Web-Nurun.pdf

Santrock, JW., 2009, Perkembangan Anak 1. Jakarta, Erlangga.

Soetjiningsih 2017, Tumbuh Kembang Anak, EGC, Jakarta.

Sunarti, E., 2004, Mengasuh Dengan Hati, Elex Media Komputindo, Jakarta

Wiyani, N. A., 2012, Bina Karakter Anak Usia Din, Ar-Ruzz Media, Yogyakarta 